\title{
Estandardização e estandardologia: notas sobre a norma linguística
}

Carlos Eduardo Deoclécio ${ }^{a}$

Marcos Bagno ${ }^{b}$

\begin{abstract}
Resumo
Abordamos inicialmente, neste artigo, a questão da norma linguística num viés mais amplo e propositivo, apresentando reflexões e um conjunto de 15 linhas de trabalho que constituem as possibilidades, a análise $e$ as ações sobre a estandardização linguística. Na sequência, desdobramos, a modo de introdução, a abordagem da estandardologia comparada que, além de reunir as contribuições das diversas correntes da Sociolinguística, é uma aposta para enriquecer o debate que se faz atualmente sobre a elaboração de uma nova norma de referência para o português brasileiro. Também apresentamos um importante referencial teórico e bibliográfico, entre autores nacionais e estrangeiros que têm atuado de forma determinante no exame e na discussão da norma, seja em sentido lato, o da normalidade dos usos da lingua, seja em sentido estrito, o da elaboração, codificação e implementação de uma norma tida como padrão/ estândar/de referência.
\end{abstract}

Palavras-chave: Norma linguística.

Norma-padrão. Estandardologia comparada.

Sociolinguística.

Recebido em: 02/10/2020 Aceito em: 11/11/2020

\footnotetext{
a Instituto Federal do Espírito Santo, campus Vitória, Vitória, ES, Brasil. E-mail: edu.letras@gmail.com

b Universidade de Brasília, Instituto de Letras, Brasília, DF, Brasil. E-mail: bagno.marcos@gmail.com
}

\section{Como citar:}

Deoclécio, C. E.; Marcos Bagno, M. Estandardização e estandardologia: notas sobre a norma linguística. Gragoatá, Niterói, v.26, n.54, p. 139-162, 2021. <https://doi.org/10.22409/gragoata.v26i54.46422> 


\section{Notas iniciais}

Uma pergunta que pode preceder qualquer reflexão envolvendo a questão da norma linguística, numa de suas especificidades, é por que normatizamos? Na verdade, é da natureza da atividade humana a adoção de práticas prescritivas. Em diferentes contextos, dos mais complexos aos mais simples, procuramos regulamentar ações, decisões, dispositivos e, com isso, acabamos por estabelecer certa cultura social normativa. Para Cameron (1995, p. 2), essa tendência das relações sociais humanas no que tange às línguas "faz parte do que é o uso da língua". Burridge (2010, p. 3), a esse respeito, diz que normatizar línguas estaria no rol de uma "[...] luta humana por controlar a natureza desregrada".

Seja qual for a resposta para a pergunta que acabamos de fazer, não se pode perder de vista que as práticas normativas ou prescritivas para línguas, na sua elaboração e também na sua implementação, estiveram, estão e estarão eivadas de critérios muitas vezes opacos, pouco ou nada científicos, marcados por traços de subjetividade, e a serviço de intenções político-ideológicas que podem ser econômicas, nacionalistas, protecionistas, puristas e/ou autoritárias. O fato de a literatura canônica retroalimentar a exemplificação dos bons e corretos usos para as línguas é apenas um desses critérios, pois ainda no século XXI, pelo menos na maioria das gramáticas de referência do português, textos literários do século XIX são utilizados para ditar como deve ser a norma-padrão para a língua que se fala e se escreve majoritariamente no Brasil.

A própria inquietação com como, para que e por que

${ }^{1}$ Para entender melhor a abordagem glotopolítica dos estudos sociolinguísticos, sugerimos a leitura do texto seminal Pour la Glottopolitique, de Guespin e Marcellesi (1986), e a visita ao site do Anuário de Glotopolítica: http:// www.glotopolitica.com. se normatiza uma língua e toda a problemática dos agentes glotopolíticos ${ }^{1}$ que a envolvem serviram de estímulo para que um conjunto de linguistas brasileiros passasse a se dedicar à temática da norma. Nesse sentido, tem havido no Brasil uma produção acadêmica importante, principalmente desde o final dos anos 1990 até os dias atuais. Não temos como mencionar todas as publicações, de modo que mencionaremos aquelas em que norma linguística, norma-padrão e norma culta são os temas principais, constituem uma de suas partes ou estão diluídas em meio a textos sobre gramática, gramatização, políticas linguísticas e ensino. Alguns desses trabalhos são: Mattos e Silva (1995, 2004); Britto (1997), Bagno (2000, 2001, 2002, 2003, 
2009, 2011); Bortoni-Ricardo (2004, 2005); Scherre (2005); Lagares e Bagno (2011); Faraco (2008, 2016, 2020); Vieira e Brandão (2013); Neves e Casseb-Galvão (2014); Lucchesi (2015); Faraco e Vieira (2016); Faraco e Zilles (2017); Lagares (2018); Vieira (2018).

Além disso, é fundamental destacar os trabalhos de investigação e aplicação em curso sobre o tema, empreendidos por linguistas e grupos de pesquisa, seja em sua dimensão mais ampla, envolvendo a ponta do processo, que é o ensino formal, seja de forma mais estrita. Embora a tarefa de nomear os envolvidos não seja fácil, salientamos as atividades de quatro grupos/projetos de pesquisa: (1) LABPEC - Laboratório de Pesquisas em Contato Linguístico, da Universidade Federal Fluminense (UFF), contando, na linha de trabalho da glotopolítica, com a atuação de Xoán Carlos Lagares, da própria UFF, e de Marcos Bagno, da Universidade de Brasília (UnB); (2) HGEL - Historiografia, Gramática e Ensino de Linguas, com sede na Universidade Federal da Paraíba (UFPB), liderado por Francisco Eduardo Vieira e com participação ativa de Carlos Alberto Faraco; (3) o projeto Ensino de gramática em três eixos, diagnose e experiências pedagógicas, que conta com experiências desenvolvidas no nível da educação básica e universitária - da licenciatura ao doutorado, passando pelo âmbito do Mestrado Profissional em Língua Portuguesa/Profletras, conduzido por Silvia Rodrigues Vieira, da Universidade Federal do Rio de Janeiro (UFRJ); (4) NormaLi - Núcleo de Estudos da Norma Linguistica, sediado na Universidade Federal de Uberlândia (UFU) e liderado por Leandro Silveira de Araújo e Daniel Mazzaro Vilar de Almeida.

Feitas essas considerações iniciais, ao longo do texto vamos refletir primeiramente de forma ampla sobre a questão da norma linguística, num exercício de proposição de trabalhos com essa temática, para, em seguida, tratarmos de uma dessas propostas, ainda de forma introdutória. Trata-se de estabelecer relações comparativas entre processos de estandardização linguística, considerando procedimentos, critérios, contextos etc., e entre modelos de elaboração. Essa é uma área que tem sido chamada em língua inglesa de comparative standardology e em língua espanhola de estandarología comparada. Para o português, optamos por estandardologia comparada, como forma de nos aproximarmos da nomenclatura que já vem sendo empregada em outras línguas românicas. 


\section{Notas a respeito do trabalho científico sobre estandardização e norma linguísticas}

De acordo com Lagares (2018, p. 174), “a padronização é uma intervenção política sobre a língua. É ela que, nas sociedades modernas, cria a Língua como objeto social reconhecível e perfeitamente delimitado, permitindo-nos identificar comunidades linguísticas diferenciadas". Ao indicar esse caminho interpretativo, ou de constatação, o autor nos conduz a pensar que forças políticas, em sentido lato, atuam na composição da estandardização linguística. Nesse sentido, a norma-padrão, como uma intervenção política sobre a língua e como resultado de uma gestão linguística, se instaura em dada comunidade por meio de decisões tomadas por determinados grupos e é assimilada - mas nem sempre - pelos indivíduos que passam pelo processo de escolarização, pois é na escola que a norma-padrão ganha protagonismo e recebe ampla divulgação.

Essa visada política em torno da norma linguística pode ser complementada se adicionarmos as atitudes apresentadas por pessoas especializadas, ou não, diante do objeto linguístico. Faraco e Zilles (2017, p. 78-84) mostram que o termo norma, de maneira ampla, pode apresentar um significado mais geral - o das "normas normais", que guiam os usos das distintas variedades linguísticas - e outro mais restrito - o da "norma normativa", que orienta os falantes em direção a um modelo de língua ideal, tido por correto, padrão a ser seguido. Nessa perspectiva, a identificação do primeiro tipo de norma se correlaciona a uma atitude descritiva, e o segundo tipo a uma atitude normativa. Essa visão se justifica quando se percebe que a norma-padrão de uma língua - como a do português - é formulada por meio de uma atitude normativa que predomina e praticamente desconsidera em seu processo os resultados obtidos pelos trabalhos de descrição linguística desenvolvidos por especialistas, os linguistas. No entanto, não se pode perder de vista que ambas as atitudes são de interesse da Linguística, como ciência da linguagem verbal, pois, para o linguista, acompanhar os processos de estandardização/padronização/ normatização e procurar compreendê-los contribui para o seu trabalho de descrição, em qualquer nível dos estudos linguísticos - o fonético-fonológico, o morfológico, o sintático, 
o semântico, o pragmático, ou qualquer combinação que se possa promover entre esses níveis da atividade linguística.

É crucial sempre reafirmar que a Linguística não tem por objetivo aniquilar a norma-padrão de uma língua a qualquer custo, como é costumeiro ouvir de integrantes da grande mídia. Ao contrário, os estudos linguísticos científicos podem proporcionar uma discussão séria e confiável dos fatos para o trabalho de elaboração de uma norma-padrão mais condizente com a língua em uso, menos artificial e mais próxima de seus falantes, uma norma que possa produzir um sentimento de reconhecimento do modelo. Por isso, é preciso entender que “[...] os linguistas não rejeitam a normatividade, mas são críticos das regras normativas artificialmente postuladas" (FARACO; ZILLES, 2017, p. 83).

Seria um dos problemas concernentes à questão da norma linguística a polissemia que a palavra norma carrega? Não acreditamos nisso, até porque não podemos negar o fato de que as palavras são, em geral e por natureza, polissêmicas e que a frequência de seu uso vai assentando os significados e os sentidos que delas advêm.

No Dicionário Houaiss da língua portuguesa (HOUAISS; VILLAR, 2009), encontramos oito acepções referentes ao termo norma. As três primeiras dizem respeito a usos gerais, algo correlato a princípio, padrão, costume, modelo, com certa nuance entre elas. A segunda acepção - padrão estabelecido, costume se aproxima da ideia de norma como algo normal, comum, estabilizado como uma prática social. As outras cinco acepções estão situadas em rubricas específicas, duas delas, a quarta e a quinta, sob o rótulo linguística e gramática: "conjunto dos preceitos estabelecidos na seleção do que deve ou não ser us[ado] numa certa língua, levando em conta fatores linguísticos e não linguísticos, como tradição e valores socioculturais" e "tudo o que é de uso corrente numa língua relativamente estabilizada pelas instituições sociais" (HOUAISS; VILLAR, 2009, 1361). O dicionário apresenta em outra entrada uma definição para norma-padrão - "norma ('regra') considerada como padrão para as demais normas" (HOUAISS; VILLAR, 2009, p. 1362).

Para o adjetivo normal, há duas entradas, das quais apenas a primeira nos interessa. Essa entrada é composta de seis acepções. Destacamos as quatro primeiras: "conforme a norma, a regra; regular"; "que é usual, comum, natural"; "sem defeitos 
ou problemas físicos ou mentais"; "cujo comportamento é considerado aceitável e comum (diz-se de pessoa)" (HOUAISS; VILLAR, 2009, p. 1361).

Ainda nos interessa o que é apresentado para os verbetes normalizar e normatizar - há também outras entradas derivadas de norma, como normativismo e normativo, mas vamos nos limitar aos verbos já indicados. Destacamos as duas primeiras acepções de normalizar: "fazer voltar ou voltar ao estado normal, à ordem; regularizar(-se)" e "estabelecer norma(s) para; normatizar, padronizar, uniformizar" (HOUAISS; VILLAR, 2009, 1361). Com relação a normatizar, temos apenas "criar normas para; normalizar" (HOUAISS; VILLAR, 2009, p. 1362).

Bagno (2003), Faraco (2008) e Lagares (2018) apresentam um bom panorama acerca do problema da terminologia referente à norma linguística alçada como modelar. Tendo isso em vista, sempre é preciso lembrar que essa "flutuação" terminológica não se dá por ausência de dedicação ao tema ou por simples debilidade teórica. Toda uma confluência de amplos fatores históricos, sociais e políticos promovem as escolhas terminológicas também. Sobre um dos significados mais recorrentes atribuídos à expressão norma culta no debate brasileiro, Faraco (2008, p. 26) observa:

A expressão norma culta passou, então, a ser usada para designar o conjunto dos preceitos da velha tradição excessivamente conservadora e pseudopurista. Ointeressante, neste caso, é observar como, nesse deslocamento do sentido da expressão, aquele conjunto de preceitos se transformou numa entidade algo etérea, fixa, desligada de qualquer perspectiva histórica e pairando soberanamente muito acima do juízo dos reles mortais. Deu-se vida e poder a esse estranho ente que passou a ter, inclusive, vontade própria: "não aceita", "não admite", "condena", "proíbe", "insiste em" este ou aquele uso.

Faraco sintetiza nessa passagem o modo como, na segunda metade do século XX, a expressão norma culta foi substituindo gradativamente no discurso e na prática pedagógica o uso de gramática e de ensino de gramática como sinônimo de ensino de português no Brasil. Convém, ainda, destacar da passagem mencionada um problema importante que é o de quem está por trás dessa norma culta. Está devidamente entranhado no discurso geral sobre ensino de português o preceito de que "a 
gramática não aceita próclise nesse caso" ou "a norma culta condena ou proíbe esta ou aquela forma de falar ou escrever". Diríamos que é um discurso semelhante ao do "o sistema não aceita essa informação", quando somos atendidos em empresas, por exemplo. Não existem agentes responsáveis por trás da proibição, da condenação e da não aceitação. O que há são a gramática e o sistema, entidades consideradas em si mesmas como verdadeiras instituições.

Afirmação semelhante faz Lagares (2018, p. 157), já não a respeito da norma culta, mas da norma-padrão:

Poucas coisas parecem tão naturais, e por isso mesmo tão difíceis de mudar, quanto a norma-padrão da língua. Ela parece estar aí desde sempre, como um vigia do nosso comportamento verbal, eterno e imutável. Na representação mais comum entre os falantes, a norma-padrão está fora da história, numa espécie de mundo das ideias platônico, em certa medida inatingível, mas nem por isso menos desejado.

A pergunta feita no início do texto - por que normatizamos? - é abrangente e respondida por muitos linguistas de diversas maneiras. Se aqui a respondermos de forma definitiva, soará certamente pretensioso. Retomamos de maneira parcial, assim, a iniciativa de Rodrigues (1966) no artigo “Tarefas da linguística no Brasil", de abordagem linguística mais ampla, que inspirou Bagno e Rangel (2005) no texto “Tarefas da educação linguística no Brasil", de visada mais pedagógica. Recentemente, Batista (2019), num trabalho de linha historiográfica, publicou "As tarefas da linguística brasileira: ciência, história e identidade social". Não vamos necessariamente propor tarefas, mas procurar demonstrar a abrangência que o tema da norma linguística apresenta, por meio de uma síntese de linhas de trabalho possíveis e com pelo menos um exemplo em cada uma delas. Sem a pretensão de esgotar todas as possibilidades, o interesse de pesquisas a respeito da norma linguística abarca, entre outros elementos:

1. O processo de elaboração ou construção da normapadrão - ou norma de referência - de uma língua, que é marcado por critérios nem sempre claros, podendo ir de considerações linguísticas a históricas, sociais, políticas e ideológicas. Por exemplo: num 
2 Para melhor entendimento do conceito e aplicação de diglossia, sugerimos a leitura de Ferguson (1959), Fishman (1967) e Wexler (1971). processo de reelaboração da norma de referência para o português brasileiro, até que ponto a tradição já estabelecida seria levada em consideração? O que poderia permanecer da prescrição para certos padrões morfossintáticos? Nesse mesmo sentido, o que não poderia continuar?

2. O contexto geopolítico desse processo de elaboração, isto é, se há convivência espacial de mais de uma língua, como se organiza o nível de bilinguismo e se os falantes estão submetidos a uma situação de diglossia ${ }^{2}$. Por exemplo: no Estado espanhol convivem, ao lado do castelhano, línguas minorizadas também oficiais em determinadas Comunidades Autônomas uma das instâncias em que se organiza a geopolítica espanhola. Temos o galego na Galiza, o euskera no País Basco, o catalão na Catalunha. Como se configura o processo de estandardização linguística em casos como esse?

3. A elaboração e a publicação de literatura normativa: manuais, gramáticas, livros didáticos e dicionários que contenham total ou parcialmente a norma linguística elaborada, assim como o acesso a eles. Por exemplo: um estudo histórico-comparativo entre gramáticas produzidas em determinada época com outras da atualidade, a fim de verificar se as contribuições trazidas pelas análises linguísticas científicas têm tido espaço em obras que tradicionalmente espelham um viés mais conservador da língua.

4. As áreas da gramática sobre as quais incide a elaboração. Por exemplo: nas seções dedicadas aos padrões normativos de concordância verbal e nominal, que tipo de estrutura ou de construção é mais abordado? O que poderia refletir o grande número de duas ou mais possibilidades de concordância para o mesmo caso que manuais e gramáticas costumam apresentar? 
5. A possível correlação entre norma-padrão e cânone literário. Por exemplo: por que persiste e resiste, em boa parte das gramáticas de referência, o critério de que os autores consagrados da literatura em língua portuguesa são o exemplo de língua a ser seguido? Existe, de algum modo, uma retroalimentação entre a norma estabelecida e a consolidação do cânone literário?

6. A definição de uma ortografia oficial e os elementos que levam a esta e não àquela opção gráfica. Por exemplo: como analisar o discurso de legitimação do Acordo Ortográfico da Língua Portuguesa de 1990? Como devem ser avaliados seus critérios, suas justificativas e sua implementação?

7. A (não) atuação de instituições, academias e órgãos reguladores em questões de estandardização ou mesmo a inexistência desses organismos. Por exemplo: órgãos como os Institutos Camões, Cervantes, Goethe, Confúcio atuam apenas na difusão das línguas e culturas a que se dedicam ou vão além? E as Academias de Letras ou de Línguas, que papel desempenham na definição de padrões linguísticos?

8. O direcionamento do código normativo elaborado: é atribuído padrão apenas à modalidade escrita de uma língua ou se prevê a modificação dos hábitos de fala, e se for assim, como isso se dá? Por exemplo: Mesmo sabendo que anos de escolarização podem promover algum tipo de mudança nos hábitos de um falante, até que ponto um usuário absorve e realiza a prescrição gramatical no percurso da escrita para a fala? E mais: o padrão elaborado é exitoso na neutralização das diferenças entre variedades de uma mesma língua?

9. A importância doalçamento das línguas vernaculares ao status de língua nacional, em especial a partir do século XVI, e o consequente empenho na criação de padrões para essas línguas - o triângulo Estado, 
${ }^{3}$ Uma língua pluricêntrica é aquela usada em distintos centros políticos, econômicos e culturais e é marcada por apresentar uma destacada variação intralinguística - as chamadas variedades, nacionais ou regionais - e também por questões identitárias e de poder. Clyne (1992) organizou o volume Pluricentric Languages, abarcando dados acerca de várias línguas pluricêntricas existentes no mundo. Desse modo, o modelo para o estudo das variedades nacionais é desenvolvido pela perspectiva da interação entre os vários centros onde determinada língua é falada, e não que um deles esteja se desviando de outro centro considerado o principal ou referencial. nação e língua. Por exemplo: quando algumas línguas românicas na Europa foram se conformando, ganhando uma escrita regular e espaço no ensino formal ao lado do latim, de que forma isso ocorreu?

10. O impacto da (não) convivência das distintas normas resultante da implantação dessas mesmas línguas nacionais em territórios invadidos. Por exemplo: já configuradas como línguas nacionais de seus respectivos Estados, o espanhol e o francês, guardadas as devidas peculiaridades, têm considerado as iniciativas endonormativas de territórios que Espanha e França colonizaram séculos atrás?

11. O ensino de língua materna, estrangeira, de herança, adicional ou outra nomenclatura possível. Ele ocorre numa perspectiva pluricêntrica ${ }^{3}$ ou não? Por exemplo: como trabalhar o tratamento de segunda pessoa no espanhol se o contexto for o de ensiná-lo como língua estrangeira para um brasileiro? A variante americana vos é considerada ao lado de tú e usted?

12. A percepção dos usuários de uma língua em relação à norma instituída, que pode estar correlacionada a outras atitudes e comportamentos pouco ou muito conservadores na vida em sociedade. Por exemplo: qual é o sentimento linguístico do brasileiro em relação à sua língua materna, quando essa é o português? Estamos nós numa situação de esquizoglossia (HAUGEN, 1962)?

13. A maneira como os meios de comunicação, principalmente a imprensa, refletem a norma e a ortografia oficiais, incluindo nesse grupo a atuação dos usuários nas redes sociais eletrônicas. Por exemplo: os casos nesse item são fartos, como a manifestação de internautas atuando como emissários da correção linguística, mas também o modo como reagem mídia e usuários diante de um elemento novo na língua como foi com o acrônimo Covid-19, em função da 
${ }^{4}$ Sugerimos a leitura de Deoclecio (2020) a esse respeito: https://www. parabolablog.com.br/ index.php/blogs/o-covid19-ou-a-covid-19 pandemia iniciada em 2020. Como grafá-lo? Em que gênero gramatical se enquadra? ${ }^{4}$

14. A relação entre a pauta da norma linguística e um projeto de educação linguística, que vai muito além do ensino de gramática, incluindo itens como a história da língua, a consciência de que uma língua não se resume à sua norma-padrão e de que a variação linguística é inerente a toda e qualquer língua, a prática do respeito linguístico e, consequentemente, a de menos preconceito linguístico. Por exemplo: educação linguística é um componente que deveria passar por várias disciplinas nas escolas, em especial e inclusive nos primeiros anos da Educação Básica. Desse modo, os cursos de Letras e Pedagogia, principalmente, têm preparado seus alunos nesse sentido? $\mathrm{O}$ que se trabalha de Linguística nesses cursos?

\section{A perspectiva da comparação entre os processos de} codificação e elaboração normativa de diferentes línguas - a estandardologia comparada. Por exemplo: se comparamos a estandardização do italiano com a do português europeu - em que coincidem e divergem?

Como já dissemos, esses 15 itens não esvaziam as possibilidades de pesquisa quando se aborda o tema norma linguística. Nem mesmo se isolam. Ao contrário, as linhas de pesquisa e os trabalhos nelas desenvolvidos em inúmeros programas de pós-graduação dentro e fora do país tendem, ao aliar propostas descritivas, discursivas, políticas e pedagógicas, a alinhavar vários desses elementos, a partir de um escopo de investigação coerente e possível. Além disso, os exemplos que demos apresentaram questões que já foram ou têm sido respondidas por pesquisadores. A função da exemplificação foi apenas a de tornar o item proposto mais claro.

Na próxima seção, vamos tratar introdutoriamente da abordagem da estandardologia comparada, citada no item (15). 


\section{Notas sobre a abordagem da estandardologia comparada}

Joseph (1987, p. 3) afirma que "o primeiro uso atestado de 'estândar/padrão' em relação à língua está em Characteristics of men, manners, opinions, times, escrito em 1711 por Anthony Ashley Cooper". Joseph (1987, p. 5) também nos informa que o termo língua padrão, em que padrão (standard) é um adjetivo, foi empregado pela primeira vez na proposta de elaboração do Oxford English Dictionary, em 1858. No entanto, a vasta literatura acerca da temática da norma e dos padrões de língua mostra como a nomenclatura para referir ao que hoje se tem chamado de norma-padrão é múltipla ao longo dos séculos de história. Podemos encontrar os termos língua literária, língua padrão, lingua standard, gramática, norma culta, norma-padrão, norma de referência e um possível exercício de análise combinatória entre os vocábulos que formam as expressões mencionadas.

Já no século XIX, o filólogo alemão Friedrich Max Müller (1823-1900) apontava a importância do estudo da estandardização linguística do ponto de vista comparativo (SCAGLIONE, 1984). O processo de padronização de uma língua - que, em linhas gerais, consiste na definição de uma variedade linguística elaborada como o padrão a ser seguido - costuma ser conflituoso e polêmico pelo fato de ser historicamente menos linguístico e mais conectado a fatores sociais, políticos, econômicos e culturais - não nos cansamos de dizer. Esse processo não é igual entre as comunidades linguísticas porque o modo como o padrão se coloca e se impõe tende a ser diferente, dada toda a atmosfera ideológica que alinhava, ou costura tortuosamente, os dispositivos da elaboração. Afirmamos, portanto, com Muljačić (1993, p. 90) que

Qualquer dialeto pode teoricamente ser transformado numa nova língua estândar. Suas chances diminuem quando a população é numericamente pequena e economicamente pobre, quando um sentimento nacional é fraco ou ausente e quando a língua dominante é uma língua mundial ou, de qualquer modo, uma língua importante com um passado glorioso e uma taxa esplêndida de crescimento cultural e econômico. [...]. Os obstáculos podem, entretanto, ser superados: o hebraico, uma língua quase sem falantes, se tornou, em sua forma modernizada, a língua oficial de um novo Estado. 
${ }^{5}$ Sugerimos, a esse respeito, a leitura de Thomas (1991) e Walsh (2016).

${ }^{6}$ Ver Soares da Silva (2010).

${ }^{7}$ Página do programa: https:// bridgingtheunbridgeable. com/
Isso significa dizer que toda e qualquer variedade de uma língua - que, em determinados contextos, pode ser chamada de dialeto - reúne condições para, por meio de um processo de planejamento linguístico, ser eleita como a língua de referência. Diante disso, fica uma pergunta: como se organiza a comunidade linguística quando uma variedade, depois de elaborada, é elevada ao posto de norma-padrão? A resposta não é objetiva. Uma consequência certeira e frequente, porém, é o fortalecimento de hábitos sociais de correção, vigilância e cultura do erro, traços recorrentes numa ideologia tipicamente prescritiva da língua. Condutas como essas têm se mostrado produtivas, eficazes, porém cerceadoras ao longo da história da cultura letrada ${ }^{5}$.

Processos de estandardização linguística podem, portanto, ser comparados, na linha de trabalho chamada estandardologia comparada (JOSEPH, 1987; DEUMERT; VANDENBUSSCHE, 2004; AMORÓS, 2008; DOLLINGER, 2019; LEBSANFT; TACKE, 2020). Em linhas gerais, todo o aparato teórico e prático dos estudos sob a designação Sociolinguística interessa ao estudo linguístico estandardológico - desde as contribuições provenientes da Dialetologia e da Sociolinguística Variacionista (e da mudança), passando pelos estudos do Contato Linguístico, até chegarmos às elaborações encontradas na Sociologia da Linguagem e nas diferentes abordagens de Políticas Linguísticas, já que a estandardização de uma língua é parte de uma proposta mais ampla de planejamento linguístico. Certos estudos comparativos têm, inclusive, se valido de procedimentos metodológicos desenvolvidos pela Sociolinguística Cognitiva ${ }^{6}$ : os métodos socioletométricos.

Alguns projetos no âmbito europeu têm atuado na perspectiva da estandardologia comparada. Como exemplos, temos:

a. Bridging the Unbridgeable: Linguists, Prescriptivists and the General Public (2011-2016)7 , do Centro de Linguística da Universidade de Leiden, nos Países Baixos, dedicado principalmente à língua inglesa;

b. Multilingualism: Empowering Individuals, Transforming Societies ${ }^{8}$, fomentado pelo Arts and Humanities 
${ }^{9}$ Página do programa: https://lanchart.hum. ku.dk/research/slice/
Research Council (AHRC) da Grã-Bretanha e apoiado pela Universidade de Cambridge;

c. Standard Language Ideology in Contemporary Europe (SLICE) ${ }^{9}$, fomentado pela Nordic Research Foundation for the Human and Social Sciences;

d. Estandarología comparada entre las lenguas de España (ECLE): La gestión contemporánea de la normatividad do qual fazemos parte -, que está em fase inicial dos trabalhos e conta com pesquisadores de diferentes instituições europeias e brasileiras, mas têm seu foco na comparação entre os processos estandardológicos do espanhol peninsular, do catalão, do galego e do euskera.

Embora tenham as suas peculiaridades, esses projetos estabelecem acordos de cooperação e perseguem objetivos comuns, como:

a. estabelecer relações entre as variedades estandardizadas e as que ficam à margem desse processo;

b. perceber como os usuários das línguas reagem diante de uma variedade linguística elaborada, para que se verifique o nível de aceitação ou de rechaço de uma norma-padrão;

c. averiguar como e se os meios de comunicação, incluídas as redes sociais, atuam no sentido de reforçar hierarquias linguísticas e sociais, não necessariamente nessa ordem;

d. identificar em sociedades predominantemente plurilíngues/multilíngues como se dá o convívio entre as normas das diferentes línguas em uso, percebendo sobretudo as estratégias utilizadas por línguas minorizadas; 
${ }^{10}$ Existe uma

iniciativa em curso de elaboração de um glossário multilíngue em estandardologia comparada. Essa ação conta com uma parceria estabelecida com o Dictionnaire Historique des Concepts Descriptifs de l'Entité Romane: https://www.atilf.fr/. e. construir uma terminologia comum para o trabalho entre as equipes de pesquisa que atuam em diferentes países e analisam a estandardização em diferentes línguas ${ }^{10}$;

f. avaliar o sucesso ou o fracasso do processo de estandardização.

No caso do projeto ECLE, em particular, há também a preocupação de analisar se o espanhol central está ou não aberto, absorvendo e legitimando outros padrões advindos de normas como as do castelhano falado nas Américas - os chamados modelos endonormativos -já que o processo de estandardização também pode ser pluricêntrico.

Consideramos importante indicar que, em termos de publicações que se valeram da linha da estandardologia comparada, temos, por exemplo, desde o trabalho de Kloss (1952) até os recentes Germanic Standardization: Past to Present, organizado por Deumert e Vandenbussche (2004), The Pluricentricity Debate: on Austrian German and other Germanic Standard Varieties, de Dollinger (2019), e o Manual of Standardization in Romance Languages, organizado por Lebsanft e Tacke (2020).

\section{Notas finais}

A temática da norma linguística, em sua especificidade de alto impacto social, que é a norma-padrão/estândar/de referência de determinada língua, tem sido historicamente motivo de inquietação, em especial para as sociedades organizadas em torno de uma cultura letrada. Essa inquietação se dá por motivos variados - como quais critérios utilizar para a elaboração dessa norma - e por envolver múltiplos fatores, como os linguísticos, históricos, geopolíticos, ideológicos e sociais em sua amplitude. A título de exemplificação, vamos encerrar este texto com a seleção de alguns momentos importantes no cenário da questão normativa e por extensão da estandardização linguística - e também com um pequeno exercício comparativo nessa linha.

Entre estudiosos de fora e de dentro do Brasil que se debruçaram sobre o tema em suas mais variadas facetas, o 
${ }^{11}$ Apresentamos a seguir os títulos das nove teses de 1929:

1. Problemas metodológicos da concepção da língua como sistema e a importância dessa concepção para as línguas eslavas;

2. Tarefas para iniciar o estudo de um sistema linguístico e, em particular, o sistema eslavo;

3. Problemas de pesquisa em torno das línguas com funções diversas;

4. Problemas atuais do eslavo eclesiástico; 5. Problemas de transcrição fonética e fonológica nas línguas eslavas;

6. Princípios de geografia linguística, sua aplicação e sua relação com a geografia etnográfica em território eslavo;

7. Problemas eslavos relativos a um atlas linguístico, especialmente lexical;

8. Problemas de método da lexicografia eslava;

9. Importância da linguística funcional para a cultura e a crítica das línguas eslavas

Sugerimos a leitura das Teses por meio da seguinte referência:

Círculo Lingüístico de Praga. Tesis de 1929. Edición y título original: Travaux $d u$

Cercle Linguistique de Prague (Prague, 1929). Traducción y bibliografía: María Inés Chamorro. Madrid:

Alberto Corazón

Editor, 1970. dinamarquês Otto Jespersen (1869-1943) tratou, entre outros aspectos, em texto de 1925, da dificuldade em estabelecer critérios válidos para a definição de uma norma reguladora e apresentou alguns que teriam orientado a pauta normativa ao longo da história, tais como (1) o aristocrático: a normapadrão toma como referência a variedade das camadas socioeconômicas mais favorecidas/altas; (2) o democrático: critério tido por inatingível, já que a norma-padrão não daria conta, por sua essência histórica e pela heterogeneidade linguística, de reunir os mais variados usos em sua constituição; (3) o lógico: critério inviável, pois, em acordo com Jespersen, Faraco e Zilles (2017, p. 105) afirmam que "[...] a língua não é lógica ou ilógica, mas alógica"; (4) o geográfico: de acordo com esse critério, uma variedade de determinada língua seria eleita para ser o modelo; (5) o literário: diz respeito à valorização da língua escrita pelos autores canônicos - provavelmente o mais antigo dos critérios de que temos conhecimento; (6) o estético: a beleza seria o parâmetro para a língua correta; algo de extrema complexidade, tendo em vista o tom subjetivo que esse critério assume; (7) o da autoridade: critério de viés explicitamente político, já que advém do que as Academias das línguas e os gramáticos determinam como padrão linguístico (FARACO; ZILLES, 2017, p. 103-109).

Em 1926, o tcheco Vilém Mathesius (1882-1945) fundou o Círculo Linguístico de Praga (CLP), na atual República Tcheca, do qual participaram os tchecos Bohuslav Havránek (1893-1978), Jan Mukařovský (1891-1975), Bohumi Trnka (1895-1984) e Josef Vachek (1909-1996), o holandês Albert W. de Groot (1892-1963), o alemão Karl Bühler (1879-1963), o sérvio Aleksandr Belić, o inglês Daniel Jones (1881-1967), os franceses Lucien Tesnière (1893-1954), Joseph Vendryes (1875-1960), Émile Benveniste (1902-1976) e André Martinet (1908-1999), e os russos Sergej Karcevskij (1889-1955), Roman Jakobson (1898-1982) e Nikolai Trubetzkoy (1890-1938). O CLP foi uma espécie de continuação do que faziam os formalistas russos. Tratava de questões linguísticas (com especial atenção às línguas eslavas), estéticas e de teoria literária. O grupo fez sua última publicação em 1939, já que o início da Segunda Guerra Mundial e a ocupação nazista interromperam o trabalho coletivo. No entanto, em outubro de 1929, ocorre em Praga o Primeiro Congresso de Filólogos Eslavos, quando se apresentam as Teses ${ }^{11}$, escritas em francês 
no Travaux du Cercle Linguistique de Prague. Uma das questões discutidas nas Teses foi empreender um debate a respeito da padronização da língua tcheca. Por isso, em 1932, outras teses são publicadas e a discussão parece estar mais apurada. Para Mathesius, os padrões linguísticos de referência deveriam ser dotados do que ele chamava de estabilidade flexível, por estar atento ao fato de que as línguas variam e mudam ao longo do tempo.

Décadas mais tarde, em especial no âmbito catalão, em território espanhol, a noção de normalização linguística passa a ser cultivada para dar conta de um amplo processo que tem em suas etapas a própria normatização, a estandardização e a codificação da língua sobre a qual o trabalho é feito. D'Andrés Díaz (2018, p. 19) nos informa que

A normalização linguística é um conjunto sistemático de ações sociopolíticas que remetem, no âmbito linguístico, à consecução de uma normalidade na convivência de duas ou mais línguas no mesmo espaço social, e mais especificamente de uma normalidade para a língua ou línguas que são minoritárias.

É compreensível que a ação da normalização linguística - em termos gerais, tornar normais os usos de determinadas línguas em múltiplos setores da sociedade - tenha se conformado no universo do bilinguismo espanhol, onde o galego na Galiza, o catalão na Catalunha e o euskera no País Basco dividem a oficialidade linguística com o espanhol. A Universidade de Santiago de Compostela, por exemplo, conta com um setor de normalização linguística e oferece cursos dessa natureza para seus estudantes, para que a língua galega possa se normalizar, ser usada naturalmente, em diferentes

${ }^{12}$ Para um amplo conhecimento da língua galega, recomendamos a leitura de Monteagudo (1999).

\section{atividades acadêmicas e sociais ${ }^{12}$.}

A partir dos anos 2000, surgiram as reflexões e proposições de Bagno (2003) com questionamentos sobre as noções de norma culta e norma-padrão na realidade brasileira, o que em Faraco (2008) recebe contornos mais extensos, incluída a norma curta: “Trata-se de um conjunto de preceitos dogmáticos que não encontram respaldo nem nos fatos, nem nos bons instrumentos normativos, mas que sustentam uma nociva cultura do erro e têm impedido um estudo adequado da nossa norma culta/ 
comum/standard." (FARACO, 2008, p. 94). Em Milroy (2011) aparece o termo ideologia da padronização; em Lucchesi (2015, p. 211-212) há uma noção de norma sociolinguística, embasada em critérios de variação e mudança linguísticas; Lagares (2018, p. 194) apresenta o termo dinâmicas normativas, que "[...] remete aos jogos de forças entre agentes sociais e instituições na disputa pelo padrão enquanto construto político". E em Lukač $(2018$, p. 3) se encontra o grassroots prescriptivism (algo como o prescritivismo que é exercido pelas pessoas não especializadas), numa análise de comentários que leitores fazem em jornais, de usuários de redes sociais etc.

Neste texto, trouxemos, portanto, uma enumeração de propostas de trabalho possíveis quando o tema norma linguística está em pauta. Reforçamos tratar-se de uma espécie de exercícioproposta, que em nenhum momento procurou superar todas as possibilidades de investigação sobre a temática. De igual modo, procuramos desenvolver, mesmo que introdutoriamente, um dos itens listados: o estudo comparativo entre processos de estandardização, a estandardologia comparada. Nosso objetivo não é pura e simplesmente importar uma abordagem de trabalho como se já não nos estivéssemos dedicando ao assunto, mas poder aprender com o que vem sendo desenvolvido fora do país, receber as contribuições possíveis, e também apresentar aos grupos de pesquisa que atuam no exterior as nossas práticas. Ao fim e ao cabo, trata-se de um intercâmbio de visões e experiências sobre um tema ao mesmo tempo áspero, polêmico, espinhoso, conflituoso, fascinante e trabalhoso: determinar modelos/padrões/estândares para um objeto de uso coletivo, inerentemente social, que é (são) a(s) língua(s) que falamos e escrevemos.

\section{Referências}

AMORÓS NEGRE, Carla. Norma y estandarización. Salamanca: Luso-española, 2008.

BAGNO, Marcos. Dramática da língua portuguesa. Tradição gramatical, mídia \& exclusão social. São Paulo: Edições Loyola, 2000 .

(org.). Norma linguística. São Paulo: Loyola, 2001. 
(org.). Linguística da norma. São Paulo: Loyola, 2002.

A norma oculta: língua \& poder na sociedade brasileira.

São Paulo: Parábola, 2003.

; RANGEL, Egon de Oliveira. Tarefas da educação linguística no Brasil. Revista Brasileira de Linguística Aplicada, Belo Horizonte, v. 5, n. 1, p. 63-81, 2005.

Não é errado falar assim! Em defesa do português brasileiro. São Paulo: Parábola, 2009.

Gramática pedagógica do português brasileiro. São Paulo: Parábola, 2011.

BATISTA, Ronaldo de Oliveira. As tarefas da linguística brasileira: ciência, história e identidade social. Revista da ABRALIN, [s. l.], v. 18, n. 1, p. 1-35, 29 nov. 2019.

BORTONI-RICARDO, Stella Maris. Educação em lingua materna: a sociolinguística na sala de aula. São Paulo: Parábola, 2004.

Nós cheguemu na escola, e agora? Sociolinguística e educação. São Paulo: Parábola, 2005.

BRITTO, Luiz Percival Leme. A sombra do caos: ensino de língua $X$ tradição gramatical. Campinas: ALB e Mercado de Letras, 1997.

BURRIDGE, Kate. Linguistic cleanliness is next to godliness: taboo and purism. English Today, [s. l.] 26(2), p. 3-13, 2010.

CAMERON, Deborah. Verbal hygiene. London: Routledge, 1995.

CLYNE, Michael. Pluricentric languages: differing norms in different nations. Berlim: Mouton de Gruyter, 1992.

D'ANDRÉS DÍAZ, Ramón. Lenguas minoritarias y estandarización. In: GIRALT LATORRE, Javier; NAGORE LAIIN, Francho. Lenguas minoritarias en Europa y estandarización. Zaragoza: Prensas de la Universidad de Zaragoza ,2018. p. 19-45. 
DEOCLECIO, Carlos Eduardo. "O" Covid-19 ou "A" Covid-19? Fatos linguísticos em tempos de pandemia. Blog da Parábola Editorial. [São Paulo]. Postado em 3 abr. 2020. Disponível em: https://www.parabolablog.com.br/index.php/blogs/o-covid19-ou-a-covid-19. Acesso em 17 set. 2020.

DEUMERT, Ana; VANDENBUSSCHE, Wim (org.). Germanic Standardization: Past to present. Amsterdam: John Benjamins Publishing, 2004.

DOLLINGER, Stefan. The Pluricentricity Debate: on Austrian German and other Germanic Standard Varieties. Vancouver: Routledge, 2019.

FARACO, Carlos Alberto. Norma culta brasileira: desatando alguns nós. São Paulo: Parábola, 2008.

História sociopolítica da língua portuguesa. São Paulo: Parábola, 2016.

;ZILLES, Ana Maria. Para conhecer norma linguística. São Paulo: Contexto, 2017.

; VIEIRA, Francisco Eduardo (org.). Gramáticas brasileiras: com a palavra, os leitores. São Paulo: Parábola, 2016.

. Por que precisamos de (novas) gramáticas normativas? HGEL - Historiografia, Gramática e Ensino de Linguas. Site do Grupo de Pesquisa. [João Pessoa]. Postado em 13 mai. 2020. Disponível em: https://www.facebook. com/HGEL-HistoriografiaGram\%C3\%A1tica-e-Ensino-deL\%C3\%ADnguas-103863294664882. Acesso em 10 set. 2020.

FERGUSON, Charles A. Diglossia. Word, [s. l.], n. 15, p. 325-340, 1959.

FISHMAN, Joshua A. Bilingualism with and without diglossia, diglossia with and without bilingualism. Journal of social issues, [s. l.], n. 23, p. 29-38, 1967.

GUESPIN, Louis; MARCELLESI, Jean-Baptiste. Pour la glottopolitique. Langages, [s. l.], n. 83, p. 5-34, 1986. 
HAUGEN, Einar. Schizoglossia and the linguistic norm. In: WOODWORTH, Elisabeth D.; DIPIETRO, Robert J. Monograph series on languages and linguistics. Washington: Georgetown University Press, n. 15, p. 63-69, 1962.

HOUAISS, Antônio; VILLAR, Mauro de Salles. Dicionário Houaiss da lingua portuguesa. Rio de Janeiro: Objetiva, 2009.

JESPERSEN, Otto. Mankind, Nation, and Individual from a Linguistic Point of View. Cambridge: Harvard University Press, 1925.

JOSEPH, John Earl. Eloquence and power. The rise of language standards and standard language. New York: Basil Blackwell, 1987.

KLOSS, Heinz. Die Entwicklung neuer germanischer Kultursprachen seit 1800. Düsseldorf: Swan, 1978 [1952].

LAGARES, Xoán Carlos. Qual política linguística?: desafios glotopolíticos contemporâneos. São Paulo: Parábola, 2018.

; BAGNO, Marcos (org.). Políticas da norma e conflitos linguísticos. São Paulo: Parábola, 2011.

LEBSANFT, Franz; TACKE, Felix (org.): Manual of Standardization in the Romance Languages. Berlin: De Gruyter, 2020.

LUCCHESI, Dante. Lingua e sociedade partidas: a polarização sociolinguística do Brasil. São Paulo: Contexto, 2015.

LUKAČ, Morana. Grassroots prescriptivism. Utrecht: LOT, 2018.

MATTOS E SILVA, Rosa Virgínia. Contradições no ensino do português: a língua que se fala $x$ a língua que se ensina. São Paulo/Salvador: Contexto/EDUFBA, 1995.

. O português são dois: novas fronteiras, velhos problemas. São Paulo: Parábola, 2004.

MILROY, James. Ideologias linguísticas e as consequências da padronização. In: LAGARES, Xoán Carlos; BAGNO, Marcos 
(org.). Políticas da norma e conflitos linguísticos. São Paulo: Parábola, 2011. p. 49-87

MONTEAGUDO, Henrique. Historia social da lingua galega. Idioma, sociedade e cultura a través do tempo. Vigo: Editorial Galaxia, 1999.

MULJAČIĆ, Žarko. Standardization in Romance. In: POSNER, Rebecca; GREEN, John N. (org.). Trends in Romance linguistics and philology: Bilingualism and linguistic conflict in Romance. Berlim: Mouton de Gruyter, 1993. p. 77-114.

NEVES, Maria Helena de Moura; CASSEB-GALVÃO, Vânia Cristina (org.). Gramáticas contemporâneas do português: com a palavra os autores. São Paulo: Parábola, 2014.

RODRIGUES, Aryon Dall'Igna. Tarefas da linguística no Brasil. Estudos Linguísticos (Revista Brasileira de Linguística Teórica e Aplicada), [s. l.], v. 1, n. 1, p. 4-15, 1966.

SCAGLIONE, Aldo. The emergence of national languages. Ravenna: Longo Editore, 1984.

SCHERRE, Maria Marta Pereira. Doa-se lindos filhotes de poodle: variação linguística, mídia e preconceito. São Paulo: Parábola, 2005.

SOARES DA SILVA, Augusto. Measuring and parameterizing lexical convergence and divergence between European and Brazilian Portuguese. In: GEERAERTS, Dirk; KRISTIANSEN, Gitte; PEIRSMAN, Yves (org.). Advances in cognitive sociolinguistics. Berlim: Mouton de Gruyter, 2010. p. 41-83.

THOMAS, George. Linguistic Purism. London: Longman, 1991.

VIEIRA, Francisco Eduardo. A gramática tradicional: história crítica. São Paulo: Parábola, 2018.

VIEIRA, Sílvia Rodrigues; BRANDÃO, Sílvia Figueiredo. Ensino de gramática: descrição e uso. 2. ed. São Paulo: Contexto, 2013.

WALSH, Olivia. Linguistic Purism: Language Attitudes in France and Quebec. Amsterdam: John Benjamins, 2016. 
WEXLER, Paul. Diglossia, language standardization and purism - parameters for a typology of literary languages. Lingua, [s. l.], n. 27, p. 330-354, 1971.

\section{Abstract \\ Standardization and standardology: notes on the linguistic norm}

In this article, we first address the issue of the linguistic norm in a broader and more propositional way, presenting some reflections and a set of 15 lines of work that make up the possibilities, analysis and actions on linguistic standardization. In the sequence, we unfolded in a tone of introduction the approach of comparative standardization, which, besides gathering the contributions of the various currents of Sociolinguistics, is a bet to enrich the debate that is currently taking place on the elaboration of a new norm of reference for Brazilian Portuguese. We also present an important theoretical and bibliographical body of references, among national and foreign authors who have acted decisively in the examination and discussion of the norm, either in a broad sense, that of the normality of the uses of the language, or in a strict sense, that of the elaboration, codification and implementation of a norm considered as a standard or reference.

Keywords: Linguistic norm. Standard language. Comparative standardology. Sociolinguistics. 
Carlos Eduardo Deoclécio é doutorando em Estudos de Linguagem na Universidade Federal Fluminense (UFF), e em Linguística na Universidade de Santiago de Compostela (USC), com bolsa pelo Programa Capes/ PrInt. Tem mestrado em Estudos Linguísticos pela Universidade Federal do Espírito Santo (Ufes), onde também se graduou em Letras/Português. É professor do Instituto Federal do Espírito Santo (Ifes), campus Vitória, desde 2010, onde atua em disciplinas de Linguística, Língua Portuguesa e Língua Espanhola.

Marcos Bagno tem graduação em Letras (Bacharelado em Língua Portuguesa) pela Universidade Federal de Pernambuco (1991), mestrado em Linguística pela Universidade Federal de Pernambuco (1995) e doutorado em Filologia e Língua Portuguesa pela Universidade de São Paulo (2000). É professor Associado do Instituto de Letras da Universidade de Brasília (UnB). É colaborador do Programa de Estudos da Linguagem da Universidade Federal Fluminense (UFF). Tem experiência na área de Linguística, com ênfase em Tradução, Sociolinguística e ensino, atuando principalmente nos seguintes temas: prática de tradução francês/português, ensino de português, sociologia da linguagem, política linguística, gramática tradicional e português brasileiro. 